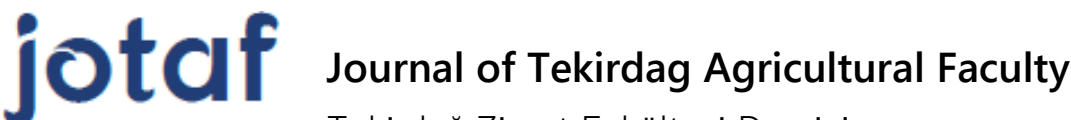 \\ Tekirdağ Ziraat Fakültesi Dergisi
}

Mayıs/May 2020, 17(2)

Başvuru/Received: 08/05/19

Kabul/Accepted: 23/11/19

DOI: $10.33462 /$ jotaf.561653

http://dergipark.gov.tr/jotaf

http://jotaf.nku.edu.tr/

ARAŞTIRMA MAKALESİ

RESEARCH ARTICLE

\section{Tarımsal Kirliliğin Trakya Bölgesi Sucul Habitatları Üzerine Etkilerinin Temel Bileşen Analizi Kullanılarak Değerlendirilmesi: Makro ve Mikro Elementler - A ğır Metaller}

Use of Principle Component Analysis to Evaluate the Effects of Agricultural Pollution on the Aquatic Habitats of Thrace Region: Macro and Micro Elements - Heavy Metals

\section{Cem TOKATLI ${ }^{1}$ İpek ATILGAN HELVACIOĞLU ${ }^{1 *}$}

\section{$\ddot{\mathbf{O} z}$}

Son yıllarda, sucul ekosistemlerin kalitesini değerlendirmek için istatistiksel uygulamaların kullanılması artı̧ göstermektedir. Temel Bileşen Analizi (PCA), çevresel kirlenmeyi değerlendirmek için yaygın olarak kullanılan güçlü birçok değişkenli istatistiksel tekniktir. Ergene Nehir Havzası, Trakya Bölgesi'nin en önemli sucul habitatıdır ve ülkemizin Marmara Bölgesi'nin kuzey-batı kesiminde yer almaktadır. Havza yoğun bir tarımsal, evsel ve endüstriyel kirlenmeye maruz kalmaktadır. Bu çalışmanın amacı, Ergene Nehri Havzası'nın lotik (akarsular) ve lentik (baraj gölleri) bileşenlerinin sularındaki makro - mikro element ve ağır metal birikimlerini ( $\mathrm{Li}, \mathrm{Be}, \mathrm{B}, \mathrm{Na}$, $\mathrm{Mg}, \mathrm{Al}, \mathrm{K}, \mathrm{Ca}, \mathrm{V}, \mathrm{Cr}, \mathrm{Mn}, \mathrm{Fe}, \mathrm{Co}, \mathrm{Ni}, \mathrm{Cu}, \mathrm{Zn}, \mathrm{As}, \mathrm{Se}, \mathrm{Sr}, \mathrm{Mo}, \mathrm{Cd}, \mathrm{Sb}, \mathrm{Ba}, \mathrm{Tl}, \mathrm{Pb}$ ) Pearson Korelasyon İndeksi (PCI) ve Temel Bileşen Analizi(PCA) kullanarak değerlendirmektir. Bu amaçla, 2018 yılı bahar mevsiminde yapılan arazi çalışmaları ile havzada belirlenen toplam 36 istasyondan örneklemeler yapılmış ve sudaki bazı mikro - makro element ve ağır metal birikimleri incelenmiştir. Çalışmamızda uygulanan PCI sonuçlarına göre, incelenen makro ve mikro elementler arasında, $\mathrm{p}<0,05$ ve $\mathrm{p}<0,01$ önem düzeylerinde anlamlı ilişkiler tespit edilmiştir. Çalışmamızda uygulanan PCA sonuçlarına göre ise, rotasyondan sonraki toplam yüzde varyansları açısından dört faktör toplam varyansın \% 87'sini açıklamıştır.

Anahtar Kelimeler: Ergene Nehir Havzası, Makro - mikro elementler, Ağır metaller, Temel Bileşen Analizi, Tarımsal kirlilik

\begin{abstract}
In recent years, the use of statistical applications to assess the quality of aquatic ecosystems has increased. Principal Component Analysis (PCA) is a powerful multivariate statistical technique commonly used to assess environmental contamination. Ergene River Basin is the most important aquatic habitat of Thrace Region and is located in the north-western part of the Marmara Region of Turkey. The basin is intensively exposed to agricultural, domestic and industrial pollution. The aim of this study was to evaluate the macro and micro element accumulations ( $\mathrm{Li}, \mathrm{Be}, \mathrm{B}, \mathrm{Na}, \mathrm{Mg}, \mathrm{Al}, \mathrm{K}, \mathrm{Ca}, \mathrm{V}, \mathrm{Cr}, \mathrm{Mn}, \mathrm{Fe}, \mathrm{Co}, \mathrm{Ni}, \mathrm{Cu}, \mathrm{Zn}, \mathrm{As}, \mathrm{Se}, \mathrm{Sr}, \mathrm{Mo}, \mathrm{Cd}, \mathrm{Sb}, \mathrm{Ba}, \mathrm{Tl}, \mathrm{Pb}$ ) in water of the lotic (lakes) and lentic (reservoirs) components of the Ergene River Basin by using Pearson Correlation Index (PCI) and Principal Component Analysis (PCA). For this purpose, water samples were collected in the spring season of 2018 from a total of 36 stations selected on the basin and some micro and macro element accumulations were determined. According to the results of PCI, significant relationships were found between the

\footnotetext{
1*Sorumlu Yazar/Corresponding Author: İpek Atılgan Helvacığlu, Trakya Üniversitesi, İpsala Meslek Yüksekokulu, Laboratuvar Teknolojisi Programı, İpsala, Edirne. E-mail: ipekhelvacioglu@gmail.com (D) OrcID: 0000-0002-3841-1206

${ }^{1}$ Cem Tokatlı, Trakya Üniversitesi, İpsala Meslek Yüksekokulu, Laboratuvar Teknolojisi Programı, İpsala, Edirne. E-mail: tokatlicem@gmail.com 0000-0003-2080-7920

Atıf/Citation: Atılgan Helvacıŏglu, İ, Tokatlı, C.2020. Tarımsal kirliliğin Trakya Bölgesi sucul habitatları üzerine etkilerinin temel bileşen analizi kullanılarak değerlendirilmesi: makro ve mikro elementler-ağır metaller, Tekirdă̆ Ziraat Fakültesi Dergisi, 17(2), 137-148.

*Bu çalışma Yüksek Lisans tezinden özetlenmiştir.

CBu çalışma Tekirdağ Namık Kemal Üniversitesi tarafindan Creative Commons Lisansı (https://creativecommons.org/licenses/by-nc/4.0/) kapsamında yayınlanmıştır. Tekirdağ 2019
} 
investigated macro and microelements in $\mathrm{p}<0.05$ and $\mathrm{p}<0.01$ significance levels. According to the PCA results, four factors explained $87 \%$ of the total variance in terms of total percentage variances after rotation.

Keywords: Ergene River Basin, Macro - micro elements, Principle Component Anlaysis, Agricultural pollution

\section{Extended Summary}

Introduction: Statistical applications have been used to evaluate water ecosystem quality in recent years. Principle Component Analysis (PCA) is a powerful multivariate statistical technique widely used to evaluate environmental contamination. Ergene River Basin is the most significant aquatic habitat of Thrace Region and it is located on the north-west part of Marmara Region in Turkey. The basin is exposed to an intensive agricultural, domestic, and industrial pollution. The aim of this study was to evaluate the macro micro element and heavy metal accumulations in water of lotic and lentic components of Ergene River Basin by using Pearson Correlation Index (PCI) and Principle Component Analysis (PCA).

Materials and Methods: For the statistical evaluation of water quality of lotic and lentic components of Ergene River Basin, some micro and macro element accumulations including $\mathrm{Li}, \mathrm{Be}, \mathrm{B}, \mathrm{Na}, \mathrm{Mg}, \mathrm{Al}, \mathrm{K}, \mathrm{Ca}$, $\mathrm{V}, \mathrm{Cr}, \mathrm{Mn}, \mathrm{Fe}, \mathrm{Co}, \mathrm{Ni}, \mathrm{Cu}, \mathrm{Zn}, \mathrm{As}, \mathrm{Se}, \mathrm{Sr}, \mathrm{Mo}, \mathrm{Cd}, \mathrm{Sb}, \mathrm{Ba}, \mathrm{Tl}, \mathrm{Pb}$ in water were investigated by using an ICPMS. Water samples were collected on the basin from 36 selected stations (21 of them were on the lotic parts and 15 of them were on the lentic parts) in spring season (rainy) of 2018. Pearson Correlation Index (PCI) and Principal Component Analysis (PCA) were performed by using "SPSS 17" statistical program.

Results and Discussion: According to the results of PCI, significant relations were found between the investigated macro and micro elements in $\mathrm{p}<0.05$ and $\mathrm{p}<0.01$ significance levels. According to the results of PCA, four factors explained $87 \%$ of the total variance in terms of total percentage variances after rotation. The most important sources of copper, boron, zinc, lead, manganese and potassium values detected in Basin waters, which were recorded in the same factor (F2) as a result of PCA, may be considered as fertilizers and pesticides used in agricultural activities. Industrial activities are known as the most important sources of molybdenum, cadmium, beryllium, antimony, chromium and vanadium. According to the results of PCA, they were recorded in the same factor (F1) and the most important source of the elements in the basin waters may be Çorlu and Ergene Rivers. 
Son yıllarda su kaynaklarında toksik element birikimlerinin araştırılması hız kazanmıştır. En önemli kirletici parametreler arasında yer alan ağır metaller, hem biyotik hem abiyotik öğelerde birikim göstermekte ve çoğu organik kirleticiler gibi biyolojik olarak indirgenemediklerinden canlılarda toksik etkiler oluşturmaktadır (Shrivastava et al, 2003; Çiçek et al., 2013; Köse et al., 2015; Tokatlı et al., 2016; Ustaoğlu et al., 2017; Ustaoğlu ve Tepe, 2019; Taş et al., 2019).

Meriç - Ergene Nehir Havzası ülkemizin en üretken tarımsal alanlarından birini teşkil etmektedir ve sistemin başlıca kullanım alanı sulama suyu teminidir. Havzanın \%95'i (1.223.263 hektar) tarıma elverişli, 328.039 hektar alan ise teknik ve ekonomik olarak sulamaya elverişlidir. Pirinç başta olmak üzere, şekerpancarı, ayçiçeği, mısır, sebze ve meyve başlıca ürün çeşitlerini oluşturmaktadır (Kibaroğlu, 2008; Tokatlı ve ark., 2014; Tokatlı, 2014; 2017; Arda ve ark., 2015).

Havzada yürütülen yoğun tarımsal faaliyetlerin yanı sıra özellikle Lüleburgaz, Çorlu ve Çerkezköy gibi yerleşim birimlerine yakın yerlerde, endüstriyel kullanım kaynaklı su kirliliği bölgenin en önemli sorunlardan biridir. Hızlı kentleşme ve sanayileşme nedeniyle ciddi bir kirliliğe maruz kaldığı bilinen Ergene Nehri, bölgenin en önemli sulama suyu kaynağını teşkil eden Meriç Nehri’nin de en önemli kollarından biridir ve havzasında yaklaşık yüzlerce sanayi kuruluşu yer almaktadır (DSİ, 1997; Tokatlı, 2015; Tokatlı ve Baştatlı, 2016). Bölge insanlarının çevre konusunda yeterince bilgi sahibi olmamaları ve çevre konusundaki hassasiyetlerinin çok düşük olması da havzanın en önemli çevre sorunları arasında yerini almaktadır (Şekil 1) (Tokatlı ve Gürbüz, 2014).

Araştırılan bölgelerde elde edilen verilerin sınıflandırılması, modellenmesi ve yorumlanması, ekosistem kalitesinin değerlendirilmesinde yapılması gereken en önemli unsurlardandır (Boyacioglu, 2006). Sistemdeki değişkenlerin çoğunun uygun bir şekilde değerlendirilebilmesi için, Temel Bileşen Analizi ve Faktör Analizi gibi multivaryete istatistik uygulamaları, sucul ekosistemler için önemli bileşenlerin ya da faktörlerin belirlenmesinde çok büyük katkılar sağlarlar (Shrestha ve Kazama, 2007). Faktör Analizi, veriler arasındaki ilişkilere dayanarak verilerin daha anlamlı ve özet bir biçimde sunulmasını sağlayan çok değişkenli bir istatistiksel analiz türüdür ve hem yeraltı hemde yüzey suları kalitesinin değerlendirilmesinde çok yaygın şekilde kullanılmaktadır (Liu et al., 2003; Amadi et al., 2010; Tokatlı et al., 2013; Tokatlı, 2014; Köse et al., 2014; Tokatlı et al., 2014; Boateng et al., 2016; Köse et al., 2018; Ustaoğlu ve Tepe, 2018; Çiçek et al., 2019).

Çalışmamızın amacı, bölge için büyük önem taşıyan ve kullanım alanı çok yaygın olan Ergene Nehir Havzası lotik (akarsular) ve lentik (barajlar) bileşenlerinde, makro - mikro element ve ağır metal birikimlerinin, Pearson Korelasyon İndeksi (PCI) ve Temel Bileşen Analizi (PCA) kullanılarak değerlendirilmesidir. 


\section{Çalıșma Alanı ve Örneklerin Toplanması}

\section{Materyal ve Yöntem}

2018 yılının ilkbahar mevsiminde yapılan arazi çalışmalarında, Ergene Nehri üzerinden, önemli yan kollardan ve havzada yer alan barajlardan olmak üzere, havzada belirlenen toplam 36 istasyondan, su örnekleri toplanmıştır. İstasyon bilgileri Tablo 1'de, ArcGIS programı kullanılarak çizilen Ergene Nehir Havzası ve seçilen istasyonlar ise Şekil 2'de verilmiştir.

Çizelge 1. İstasyon bilgileri (Ergene Nehir Havzası)

Table 1. Station information (Ergene River Basin)

\begin{tabular}{|c|c|c|c|}
\hline İstasyon & Konum & İstasyon & Konum \\
\hline \multicolumn{4}{|c|}{ Akarsular } \\
\hline \multicolumn{2}{|c|}{ Meriç ve Ergene Nehirleri } & \multicolumn{2}{|c|}{ Yan Kollar } \\
\hline E1 & Kavacık & T1Safaalan Çayı & Karlı \\
\hline E2 & Muratlı & T2Çorlu Çayı & Muratlı \\
\hline E3 & Karamusul & T3Ahmetbey Çayı & Ahmetbey \\
\hline E4 & Eskibedir & T4Köprüaltı Çayı & Lüleburgaz \\
\hline E5 & Oklalı & T5Anadere Çayı & Sinanlı \\
\hline E6 & Pehlivanköy & T6Hayrabolu Çayı & Karakavak \\
\hline E7 & Uzunköprü & T7Büyükdere Çayı & Babeski \\
\hline E8 & Yenicegörece & T8Kuleli Çayı & Kumköy \\
\hline E9 & Adasarhanlı & T9Ana Dere & Bakışlar \\
\hline M1 & Küplü & T10Sulama Kanalı & Küçükaltıağaç \\
\hline \multicolumn{4}{|c|}{ Sarıcaali } \\
\hline \multicolumn{4}{|c|}{ Barajlar } \\
\hline \multicolumn{2}{|c|}{ Kayalıköy Barajı } & \multicolumn{2}{|c|}{ Kırklareli Barajı } \\
\hline KKD1 & K.Ü. Rektörlük & KD1 & Kırklareli \\
\hline KKD2 & K.Ü. Rektörlük & KD2 & Kırklareli \\
\hline KKD3 & Karahamza & KD3 & Kırklareli \\
\hline \multicolumn{2}{|c|}{ Süloğlu Barajı } & \multicolumn{2}{|c|}{ Karaidemir Barajı } \\
\hline SD1 & Süloğlu & KDD1 & Kozyörük \\
\hline \multirow[t]{2}{*}{ SD2 } & Süloğlu & KDD2 & Sarnıç \\
\hline & & KDD3 & Karaidemir \\
\hline \multicolumn{2}{|c|}{ Sultanköy Barajı } & \multicolumn{2}{|c|}{ Altınyazı Barajı } \\
\hline SKD1 & Sultanköy & AD1 & Altınyazı \\
\hline SKD2 & Sultanköy & $\mathrm{AD} 2$ & Altınyazı \\
\hline
\end{tabular}




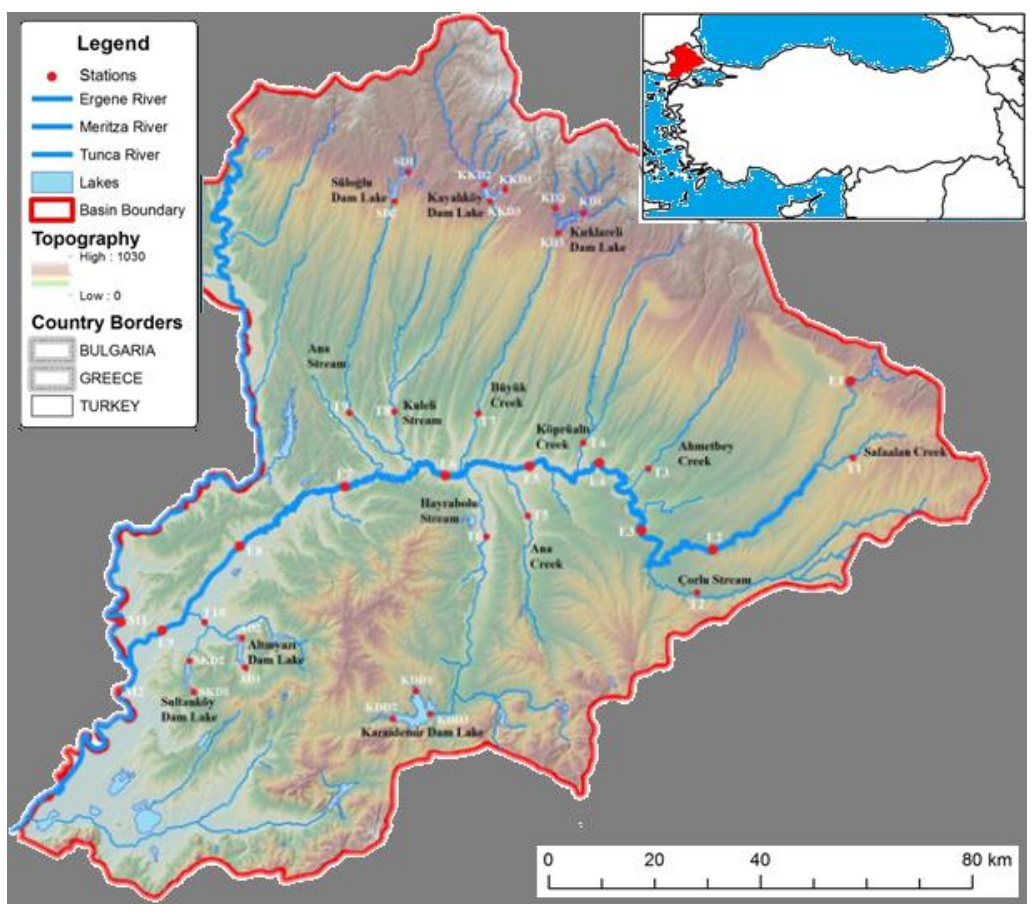

Şekil 2. Ergene Nehir Havzası ve seçilen istasyonlar

Figure 2. Ergene River Basin and selected stations

\section{Element Analizleri}

Arazi çalışmaları sırasında uygun şekilde toplanıp etiketlenen, Ergene Havzası su örneklerinin makro - mikro element ve ağır metal içerikleri, Dünya Akreditasyon Kurumu'nun ülkemizdeki temsilcisi olan TÜRKAK tarafından verilen TS EN/ISO IEC 17025 kapsamında uluslararası akreditasyon sertifikasına sahip, Trakya Üniversitesi Teknoloji Araştırma ve Geliştirme Uygulama ve Araştırma Merkezi (TÜTAGEM)'nde tespit edilmiştir.

Laboratuvara getirilen su örnekleri, çözünmüş elementlerin belirlenmesi için öncelikle, $0.45 \mu \mathrm{m}$ gözenek çaplı membran filtreden (selüloz nitrat) süzülmüştür. Süzüntüden alınan bir miktar su numunesi $(1+1)$ nitrik asit ile hemen $\mathrm{pH}<2$ 'ye ayarlanmıştır. Örneğin asit derişimi \% 1 (v/v) nitrik asite karşılık gelecek şekilde, uygun hacimde $(1+1)$ nitrik asit (ör; $20 \mathrm{~mL}$ örneğe $0.4 \mathrm{~mL}(1+1) \mathrm{HNO}_{3}$ ) ilave edilmiştir. Tüp kapatılıp karıştırılarak, örnek analize hazır hale getirilmiştir. Daha sonra su numunelerindeki toksik element seviyeleri AGILENT 7700X ICP - MS cihazı ile belirlenmiştir (EPA metod 200.8, 1994).

\section{İstatistiksel Analizler}

Elde edilen veriler arasındaki anlamlı ilişkilerin tespiti için kullanılan Pearson Korelasyon İndeksi (PCI) ve sistem üzerindeki baskı unsurlarının sınıflandırılması için kullanılan Temel Bileşen Analizi (PCA) ise “SPSS 17” istatistik programı kullanılarak yapılmıştır.

\section{Bulgular}

\section{Pearson Korelasyon İndeksi (PCI)}

Araştırma sonucu elde edilen veriler arasında istatistiki olarak anlamlı ilişkiler olup olmadığını tespit edebilmek için $(\mathrm{p}<0,05$ veya $\mathrm{p}<0,01)$, verilere Pearson Korelasyon İndeksi uygulanmıştır. Ergene Nehir Havzası sularında tespit edilen element verileri arasında kaydedilen anlamlı istatistiki ilişkiler ve korelasyon katsayıları Tablo 2'de ( $\mathrm{n}=36)$ verilmiştir. 
Tablo 2.Ergene Nehir Havzası yüzey sularında tespit edilen element verileri arasındaki ilişkiler

Table 2. The relationships between elemental data detected in surface waters of the river basin

\begin{tabular}{|c|c|c|c|c|c|c|c|c|c|c|c|c|c|c|c|c|c|c|c|c|c|c|c|c|c|}
\hline & $\mathbf{L i}$ & $\mathrm{Be}$ & B & $\mathrm{Na}$ & Mg & Al & $\mathbf{K}$ & $\mathrm{Ca}$ & $\mathbf{V}$ & $\mathrm{Cr}$ & Mn & $\mathrm{Fe}$ & Co & $\mathrm{Ni}$ & $\mathrm{Cu}$ & $\mathbf{Z n}$ & As & $\mathrm{Se}$ & $\mathrm{Sr}$ & Mo & Cd & Sb & Ba & TI & $\mathbf{P b}$ \\
\hline $\mathbf{L i}$ & 1 & & & & & & & & & & & & & & & & & & & & & & & & \\
\hline $\mathbf{B e}$ & ,038 & 1 & & & & & & & & & & & & & & & & & & & & & & & \\
\hline B &, $955^{* *}$ & ,199 & 1 & & & & & & & & & & & & & & & & & & & & & & \\
\hline $\mathrm{Na}$ &, $417^{*}$ &, $428^{* *}$ &, $649^{* *}$ & 1 & & & & & & & & & & & & & & & & & & & & & \\
\hline Mg &, 112 &,- 298 & ,063 & ,029 & 1 & & & & & & & & & & & & & & & & & & & & \\
\hline Al &,- 099 & ,099 &,- 094 &,- 033 &,- 320 & 1 & & & & & & & & & & & & & & & & & & & \\
\hline $\mathbf{K}$ & ,609** &, $339^{*}$ &, $792^{* *}$ &, $929^{* *}$ & ,069 &,- 080 & 1 & & & & & & & & & & & & & & & & & & \\
\hline $\mathrm{Ca}$ &, $388^{*}$ &,- 111 &, $360^{*}$ &, 218 &, $586^{* *}$ &,$- 388^{*}$ &, $399^{*}$ & 1 & & & & & & & & & & & & & & & & & \\
\hline $\mathbf{V}$ &, $459^{* *}$ &, $445^{* *}$ &, $673^{* *}$ &, $951^{* *}$ & ,006 &,- 024 &, $944^{* *}$ &, 325 & 1 & & & & & & & & & & & & & & & & \\
\hline $\mathrm{Cr}$ &, 328 &, $479^{* *}$ &, $546^{* *}$ &, $907^{* *}$ &,- 065 &,- 014 &, $865^{* *}$ & ,137 &, $905^{* *}$ & 1 & & & & & & & & & & & & & & & \\
\hline Mn &, $580^{* *}$ &, $451^{* *}$ &, $757^{* *}$ &, $882^{* *}$ &,- 149 & ,013 &, $913^{* *}$ &, 156 &, $873^{* *}$ &, $875^{* *}$ & 1 & & & & & & & & & & & & & & \\
\hline $\mathrm{Fe}$ & ,202 &, $470^{* * *}$ &, $373^{*}$ &, $661^{* *}$ &,- 243 &, $663^{* *}$ &, $585^{* *}$ &,- 145 &, $692^{* *}$ &, $675^{* *}$ & ,640** & 1 & & & & & & & & & & & & & \\
\hline Co &, $458^{* *}$ &, $457^{* *}$ &, $613^{* * *}$ &, $758^{* *}$ &,- 072 &,- 041 &, $823^{* * *}$ &, 230 &, $787^{* *}$ &, $916^{* *}$ & $829^{* *}$ &, $529^{* *}$ & 1 & & & & & & & & & & & & \\
\hline $\mathbf{N i}$ &, $386^{*}$ &, $377^{*}$ &, $531^{* *}$ &, $699^{* *}$ &,- 081 &,- 031 &, $750^{* *}$ & , 124 &, $710^{* * *}$ & $898^{* *}$ &, $774^{* *}$ & $496^{* *}$ &, $980^{* * *}$ & 1 & & & & & & & & & & & \\
\hline $\mathbf{C u}$ &, $412^{*}$ & $390^{*}$ &, $617^{* *}$ &, $857^{* *}$ &,- 126 &,- 043 &, $828^{* *}$ &, 147 & $858^{* *}$ &, $840^{* *}$ & $803^{* *}$ &, $588^{* *}$ &, $760^{* * *}$ &, $731^{* *}$ & 1 & & & & & & & & & & \\
\hline $\mathbf{Z n}$ & ,679** &, $413^{*}$ &, $816^{* *}$ &, $786^{* *}$ &,- 128 &,- 020 &, $893^{* *}$ &, 234 &, $827^{* *}$ &, $835^{* *}$ &, $932^{* *}$ &, $572^{* *}$ & $890^{* * *}$ &, $843^{* *}$ &, $835^{* * *}$ & 1 & & & & & & & & & \\
\hline As &, $390^{*}$ &, $404^{*}$ & ,618** &, $961^{* *}$ &, 060 &,- 073 &, $932^{* *}$ &, 313 &, $958^{* *}$ & $893^{* *}$ & $848^{* *}$ &, $613^{* *}$ &, $782^{* * *}$ &, $719^{* *}$ &, $841^{* *}$ &, $790^{* * *}$ & 1 & & & & & & & & \\
\hline Se &, $369^{*}$ &, $488^{* *}$ &, $578^{* * *}$ &, $872^{* *}$ &,- 048 &,- 038 &, $838^{* *}$ &, 191 &, $939^{* * *}$ &, $901^{* *}$ &, $818^{* *}$ &, $716^{* *}$ &, $742^{* * *}$ &, $689^{* *}$ &, $815^{* * *}$ &, $783^{* * * *}$ &, $861^{* *}$ & 1 & & & & & & & \\
\hline $\mathbf{S r}$ &, $332^{*}$ &,- 082 &, $353^{*}$ &, $395^{*}$ &, $777^{* *}$ &,$- 348^{*}$ &, $494^{* * *}$ & $861^{* *}$ &, $438^{* *}$ & ,282 & ,233 &,- 003 &, 282 & ,206 & ,218 & ,253 &, $474^{* *}$ &, 317 & 1 & & & & & & \\
\hline Mo & ,285 &, $782^{* *}$ &, $502^{* *}$ & $806^{* *}$ &,- 164 &,- 042 &, $739^{* *}$ & ,085 & $854^{* *}$ &, $828^{* *}$ &, $773^{* *}$ &, $664^{* *}$ & ,698** &, $625^{* *}$ &, $721^{* *}$ &, $714^{* * *}$ &, $794^{* *}$ &, $904^{* *}$ & ,194 & 1 & & & & & \\
\hline Cd &, 261 &, $936^{* *}$ &, $433^{* *}$ &, $582^{* *}$ &,- 243 & ,003 &, $538^{* *}$ &,- 017 &, $593^{* *}$ &, $600^{* *}$ & ,617 &, $493^{* *}$ &, $587^{* *}$ &, $506^{* *}$ &, $524^{* * *}$ &, $590^{* * *}$ &, $562^{* * *}$ &, $603^{* *}$ & ,032 &, $869^{* *}$ & 1 & & & & \\
\hline Sb &, 270 &, $554^{* *}$ &, $523^{* * *}$ &, $970^{* *}$ &,- 066 & ,004 &, $836^{* *}$ & ,088 &, $893^{* * *}$ & $868^{* *}$ &, $817^{* *}$ &, $661^{* * *}$ &, $691^{* * *}$ &, $632^{* *}$ & $809^{* * *}$ &, $684^{* * * *}$ &, $914^{* *}$ &, $818^{* * *}$ & ,273 &, $835^{* *}$ &, $669^{* * *}$ & 1 & & & \\
\hline Ba & ,257 &,- 085 & ,266 & ,236 &, $491^{* *}$ &,- 183 &, $392^{*}$ &, $874^{* *}$ &, $343^{*}$ & ,130 & ,131 &,- 020 & , 197 & ,088 &, 154 & ,158 &, $339^{*}$ &, 161 &, $789^{* *}$ & ,054 &,- 032 &, 134 & 1 & & \\
\hline Tl &, 205 &, $941^{* *}$ &, $373^{*}$ &, $557^{* *}$ &,- 270 &, 012 &, $517^{* *}$ &,- 041 &, $585^{* *}$ &, $660^{* *}$ &, $622^{* *}$ &, $504^{* *}$ &, $676^{* * *}$ & ,616 &, $536^{* * *}$ &, $615^{* * *}$ &, $551^{* *}$ &, $620^{* * *}$ &,- 001 & $866^{* *}$ &, $969^{* *}$ &, $638^{* *}$ &,- 064 & 1 & \\
\hline $\mathbf{P b}$ &, $700^{* *}$ &, $497^{* *}$ &, $836^{* * *}$ &, $808^{* *}$ &,- 264 & ,204 &, $834^{* *}$ & ,093 &, $800^{* *}$ &, $750^{* *}$ &, $914^{* *}$ &, $704^{* *}$ &, $723^{* * *}$ & ,647 &, $745^{* * *}$ &, $871^{* * *}$ &, $742^{* *}$ &, $724^{* * *}$ &, 117 &, $725^{* *}$ &, $652^{* * *}$ &, $766^{* * *}$ & ,092 &, $617^{* * *}$ & 1 \\
\hline
\end{tabular}




\section{Temel Bileşen Analizi (FA)}

Korele veriler kullanılarak, Ergene Nehir Havzası yüzey suları üzerinde etkili değişken faktölerinin belirlenmesi amacıyla Faktör Analizi kullanılmıştır.

Ergene Nehir Havzası yüzey sularında su kalitesi üzerine etkili değişken faktörlerin belirlenebilmesi için suda tespit edilen makro ve mikro element parametrelerinden toplamda 19 değişken kullanılmıştır. Elde edilen KMO (Kaiser-Meyer-Olkin) Örneklem Yeterliliği Testi sonuçları, örneklem büyüklüğünün oldukça iyi bir seviyede ve yeterli olduğunu göstermektedir $(0,732)$. Birden büyük olan özdeğerler, kullanılan verilerden açıklanması gereken varyans kaynakları olarak, temel bileşenlerin değerlendirilmesi amacıyla kriter olarak seçilmiştir ve temel bileşenlerin özdeğerlerinin ifade edildiği ScreePlot Şekil 3'te verilmiştir.

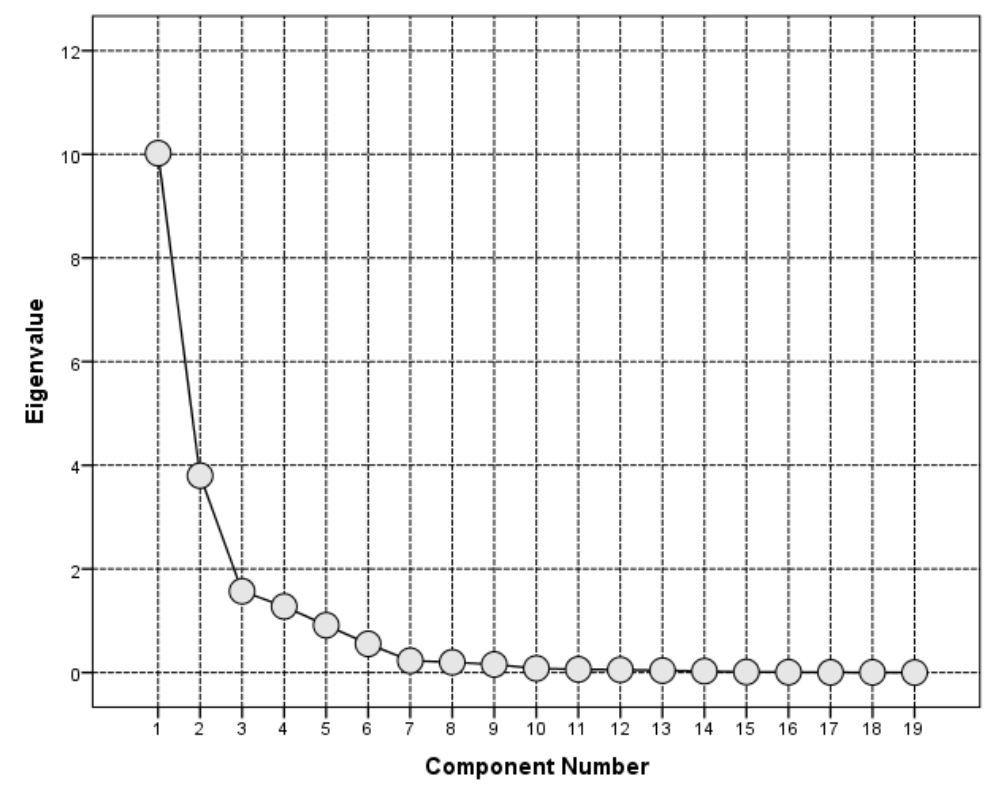

Şekil 3. ScreePlot diyagramı

Figure 3. ScreePlot diagram

Yüzde varyans değerleri, kümülatif yüzde varyans değerleri ve bileşen yükleri (rotasyondan önce ve rotasyondan sonra) Tablo 3'te, rotasyondan sonraki faktör yüklerini gösteren örümcek diyagramı ise Şekil 4'te verilmiştir. Rotasyondan sonraki toplam yüzde varyanslarına göre, 4 faktör toplam varyansın \%87'sini açıklamaktadır. Rotasyondan önceki ve rotasyondan sonraki, 4 faktör için belirlenen 0,5 'ten büyük parametre yükleri (bileşen matriksi) Tablo 4’te verilmiştir.

Tablo 3. Açıklanan toplam varyanslar

Table 3. Total variances explained

\begin{tabular}{|c|c|c|c|c|c|c|c|c|c|}
\hline \multirow[t]{2}{*}{ Bileşen } & \multicolumn{3}{|c|}{ İlk Özdeğerler } & \multicolumn{3}{|c|}{$\begin{array}{l}\text { Yüklerin Karesinin Ekstraksiyon Toplamları } \\
\text { (rotasyondan önce) }\end{array}$} & \multicolumn{3}{|c|}{$\begin{array}{c}\text { Yüklerin Karesinin Rotasyon } \\
\text { Toplamları } \\
\text { (rotasyondan sonra) }\end{array}$} \\
\hline & Toplam & $\begin{array}{c}\text { Varyans } \\
\%\end{array}$ & $\begin{array}{c}\text { Kümülatif } \\
\%\end{array}$ & Toplam & Varyans $\%$ & $\begin{array}{c}\text { Kümülatif } \\
\%\end{array}$ & Toplam & $\begin{array}{c}\text { Varyans } \\
\%\end{array}$ & $\begin{array}{c}\text { Kümülatif } \\
\%\end{array}$ \\
\hline 1 & 10,021 & 52,741 & 52,741 & 10,021 & 52,741 & 52,741 & 6,560 & 34,529 & 34,529 \\
\hline 2 & 3,799 & 19,993 & 72,734 & 3,799 & 19,993 & 72,734 & 4,822 & 25,380 & 59,909 \\
\hline 3 & 1,569 & 8,259 & 80,994 & 1,569 & 8,259 & 80,994 & 3,551 & 18,691 & 78,599 \\
\hline 4 & 1,275 & 6,713 & 87,706 & 1,275 & 6,713 & 87,706 & 1,730 & 9,107 & 87,706 \\
\hline
\end{tabular}




\section{Ekstraksiyon Metodu: Temel Bileșen Analizi}

\section{Tablo 4. Bileşen matriksleri}

Table 4. Component matrixes

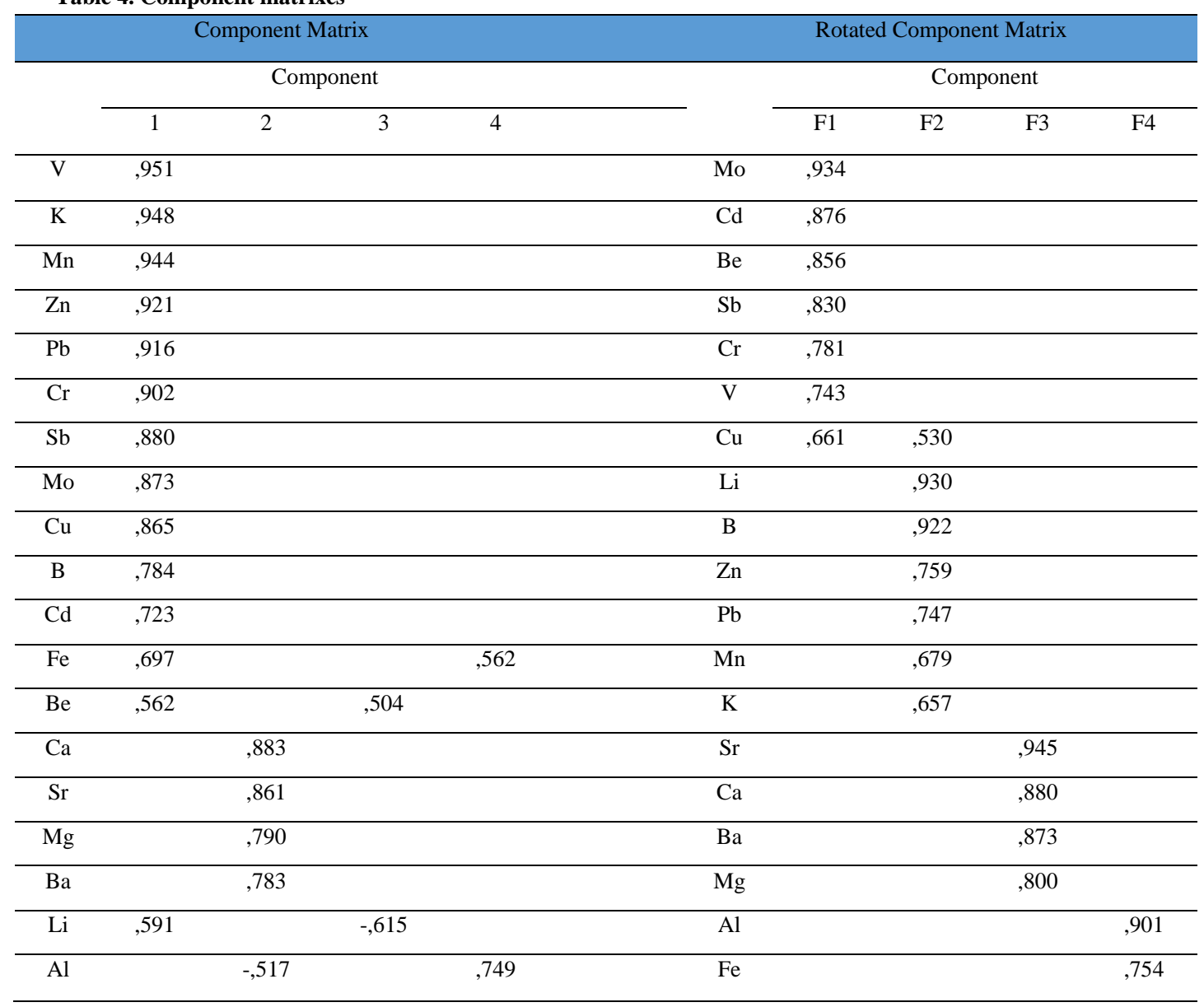

Ekstraksiyon Metodu: Temel Bileşen Analizi;

Rotasyon Metodu: KaiserNormalizasyonu ile Varimaks

Birinci faktör, toplam varyansın \%34,5'ini açıkladı ve $\mathrm{Mo}, \mathrm{Cd}, \mathrm{Be}, \mathrm{Sb}, \mathrm{Cr}, \mathrm{V}$ ve $\mathrm{Cu}$ değişkenleriyle ilişkili olarak tespit edildi. Bu faktörde, $\mathrm{Mo}, \mathrm{Cd}, \mathrm{Be}$ ve $\mathrm{Sb}$ parametreleri güçlü pozitif ve $\mathrm{V}$ ve $\mathrm{Cu}$ parametreleri orta pozitif seviye yüklü olarak belirlenmiştir. İkinci faktör, toplam varyansın \%25,3'ünü açıkladı ve Cu, $\mathrm{Li}, \mathrm{B}$, $\mathrm{Zn}, \mathrm{Pb}, \mathrm{Mn}$ ve K değişkenleriyle ilişkili olarak tespit edildi. Bu faktörde, Li, B ve Zn parametreleri güçlü pozitif ve $\mathrm{Cu}, \mathrm{Pb}, \mathrm{Mn}$ ve $\mathrm{K}$ parametreleri orta pozitif seviye yüklü olarak belirlendi. Üçüncü faktör, toplam varyansın \%18,6'sı açıkladı ve $\mathrm{Sr}, \mathrm{Ca}, \mathrm{Ba}$ ve $\mathrm{Mg}$ değişkenleriyle ilişkili olarak tespit edildi. Bu faktörde, tüm parametreler güçlü pozitif yüklü olarak belirlendi. Dördüncü faktör, toplam varyansın \%9,1'i açıkladı ve Al ve Fe değişkenleriyle ilişkili olarak tespit edildi. Bu faktörde, tüm parametreler güçlü pozitif yüklü olarak belirlendi (Şekil 4). 


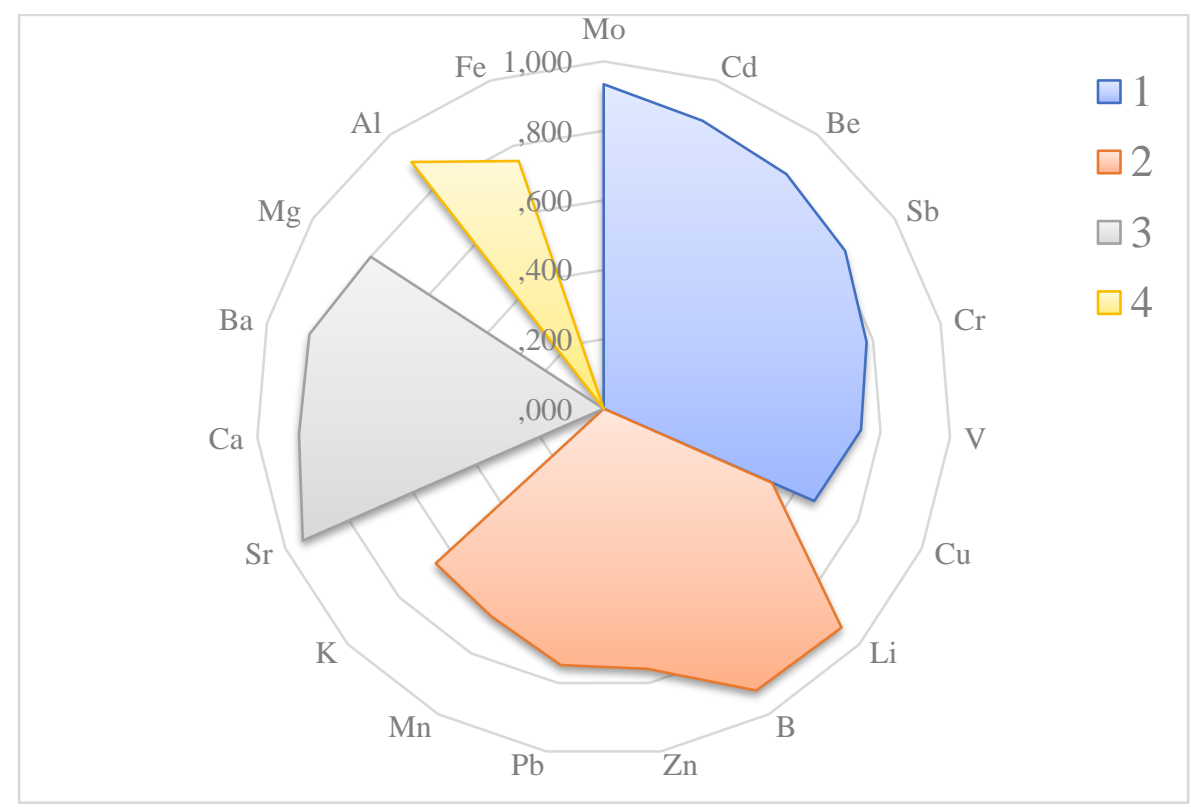

Şekil 4. Rotasyondan sonraki bileşen yükleri

Figure 4. Component loads after rotation

Çorlu Çayı ve Ergene Nehri yukarı havzasında bir çok sanayi tesisi yer almaktadır ve çok yoğun şekilde endüstriyel faaliyetler yürütülmektedir. Bu durumun, ilgili akarsuları çok önemli öçüde kirlettiği ve su kalitelerinde belirgin düşülere neden olduğu birçok araştırmacı tarafından bildirilmiş̧tir (Tokatlı, 2015; 2019a; 2019b; Tokatlı ve Baştatlı, 2016; Tokatlı ve ark., 2016; ). Molibden, kadmiyum, berilyum, antimon, krom ve vanadyumun en önemli kaynaklarından birinin endüstriyel faaliyetler olduğu bilinmektedir (ATSDR, 2002; 2012a; 2012b; 2012c; 2017; 2019). PCA sonuçlarına göre, bu elementlerin aynı faktör içerisinde yer alması (F1), bunların aynı kaynaktan sisteme giriş yaptı̆ğına işaret etmektedir ve havza sularında tespit edilen molibden, kadmiyum, berilyum, antimon, krom ve vanadyum elementlerinin en önemli kaynağının Çorlu Çayı ve Ergene Nehri yukarı havzasında yürütülen sanayi faaliyetleri olduğu düşünülmektedir.

Çinko, yerkabuğunda en bol bulunan elementlerden biridir ve doğal süreçler ile insan aktiviteleri sonucu havaya, toprağa ve suya geçmektedir. Bilindiği gibi gübreler toprağa çinko geçişinde önemli bir etkiye sahiptir ve yağmurlar havadan ve topraktan sulara çinko geçişini hızlandırabilir (ATSDR, 2005). Bakır, doğal olarak kayaçlarda, toprakta, suda ve düşük konsantrasyonlarda havada bulunan kırmızımsı bir metaldir ve insanlarda dâhil olmak üzere tüm canlılar için düşük seviyelerde esansiyel bir elementtir. Bakırın çevreye geçişi birçok yolla meydana gelebilmektedir ve bunlardan en önemlileri doğal kaynaklı geçişler, çöplükler, evsel atık sular, fosil yakıtların yakılması, fosfatlı gübre üretimidir (ATSDR, 2004). Kurşun, yerkabuğunda oldukça küçük miktarlarda bulunmaktadır ve yüzey su ve sedimentlerindeki kurşun akümülasyonlarının yaklaşı \% 90 '1 insan aktivitelerinden kaynaklanmaktadır (ATSDR, 2007). Tarım arazilerinde kullanılan pestisitler önemli miktarlarda kurşun içerebilmektedir ve kurşun, atmosferden ya da direkt olarak toprağa geçtikten sonra toprak partiküllerine kuvvetlice yapışır ve kalıntıları toprağın üst tabakasında uzun süre kalabilir. Buda tarım arazilerine sadece bugünkü değil geçmişteki pestisit uygulamalarının bile, topraktaki kurşun içeriklerinin önemli kısmından sorumlu olabileceği anlamına gelmektedir (ATSDR, 2007). Çalışmamızda uygulanan Faktör Analizi sonuçlarına göre, çinko, bakır ve kurşun aynı faktör içerisinde yer almaktadır (F2) ve bu durum, bu elementlerin sistemdeki kaynaklarının benzer faaliyetler olduğunu düşündürmektedir.

Bilindiği gibi, spesifik ağır metaller arasında gözlenen yüksek korelasyonlar, bunların aynı kaynaklardan sisteme deşarj edildiğinin bir göstergesidir (Hakanson ve Jansson, 1983; Li et al, 2009). Suda tespit edilen $\mathrm{Zn}$ ve $\mathrm{Cu}$ seviyeleri arasında istatistiki olarak anlamlı pozitif ilişkiler tespit edilmiştir $(\mathrm{p}<0,01)$. Ayrıca yine suda önemli tarımsal orijinli toksik ve esansiyel elementler olan $\mathrm{Cd}$ ile $\mathrm{Cu}$ ve $\mathrm{Zn}$ ve pestisitlerde 
yaygın olarak kullanılan $\mathrm{As}$ ve $\mathrm{Pb}$ seviyeleri arasında da istatistiki olarak anlamlı pozitif ilişkiler tespit edilmiştir $(\mathrm{p}<0,01)$. Bu elementlerin sistemdeki en önemli kaynaklarının tarımsal uygulamalar olduğu düşünülmektedir.

Bölgede monokültür yaklaşımlı tarımsal uygulamalar toprağı bazı mineraller açısından fakirleştirmektedir. Mineral açığını gidermek için ise tüm tarımsal üretim yapılan sahalarda inorganik ve fosfatlı gübreler yoğun şekilde kullanılmaktadır. Bölge sularında tespit edilen bakır, bor, çinko, kurşun, mangan ve potasyum değerlerinin en önemli kaynaklarının tarımsal faaliyetlerde kullanılan gübreler ve pestisitler olduğu düşünülmekledir. Bilindiği gibi molibden, kadmiyum, berilyum, antimon, krom ve vanadyum en önemli kaynaklarından biri endüstriyel atıklardır ve çalışmamızda Temel Bileşen Analizi sonuçlarına göre aynı faktör içerisinde yer alan (F1) bu elementlerin, havza sularındaki en önemli kaynağının ise Çorlu ve Ergene Nehirleri olduğu düşünülmektedir.

\section{Teşekkür}

Bu araştırma, Trakya Üniversitesi Bilimsel Araştırma Projeleri Birimi (TÜBAP 2017/211) tarafindan finansal olarak desteklenmiştir. 


\section{Kaynakça/References}

Amadi, A. N.,Yisa, J., Okoye, N. O., Okunlola, I. A., 2010. Multivariate Statisticale Valuation of the Hydrochemical Facies in Aba, Southeastern Nigeria. An International Journal of Biological and Physcal Sciences, 15 (3): 326-337.

Arda, H., Helvacıoğlu, İ. A., Meriç, Ç., Tokatlı, C., 2015. İpsala İlçesi (Edirne) Toprak ve Pirinç Kalitesinin Bazı Esansiyel ve Toksik Element Birikimleri Açısından Değerlendirilmesi. Tarım Bilimleri Araştırma Dergisi, 8 (1): 7-13.

ATSDR (Agency for Toxic Substances and Disease Registry), 2002. Toxicological Profile for Beryllium. Atlanta, GA: U.S. Department of Health and Human Services.

ATSDR (Agency for Toxic Substances and Disease Registry), 2004. Toxicological profile for Copper, U.S. Department of Health and Human Services.

ATSDR (Agency for Toxic Substances and Disease Registry), 2005. Toxicological profile for Zinc, U.S. Department of Healthand Human Services.

ATSDR (Agency for Toxic Substances and Disease Registry), 2007. Toxicological Profile for Lead. U.S. Department of Healthand Human Services.

ATSDR (Agency for Toxic Substances and Disease Registry), 2012a. Toxicological Profile for Cadmium. Atlanta, GA: U.S. Department of Health and Human Services.

ATSDR (Agency for Toxic Substances and Disease Registry), 2012b. Toxicological Profile for Chromium. Atlanta, GA: U.S. Department of Health and Human Services.

ATSDR (Agency for Toxic Substances and Disease Registry), 2012c.Toxicological Profile for Vanadium. Atlanta, GA: U.S. Department of Health and Human Services.

ATSDR (Agency for Toxic Substances and Disease Registry), 2017. Toxicological Profile for Molybdenum. Atlanta, GA: U.S. Department of Health and Human Services.

ATSDR (Agency for Toxic Substances and Disease Registry), 2019. Toxicological Profile for Antimony. Atlanta, GA: U.S. Department of Health and Human Services.

Boateng, T. K.,Opoku, F., Acquaah, S. O., Akoto, O., 2016. Ground Water Quality Assessment Using Statistical Approach and Water Quality Index in Ejisu-Juaben Municipality, Ghana. Environ Earth Sci, 75: 489.

Boyacioglu, H., 2006. Surface Water Quality Assessment Using Factor Analysis. Water S.A., 32(3), 389-393.

Çiçek, A., Tokatlı, C., Köse, E., 2013. Ecologıcal Rısk Assessment of Heavy Metals in Sedıment of Felent Stream (Sakarya Rıver Basın, Turkey). Pakisan Journal of Zoology, 45 (5): 1335-1341.

Çiçek, A., Köse, E., Tokatlı, C., 2019. Use of Factor Analysis to Evaluate the Sediment Quality of a Significant Mining Area: Seydisuyu Stream Basin (Turkey). Polish Journal of Environmental Studies, 28 (3): 2021-2025.

EPA method 200.8, 1994. Determination of Trace Elements in WatersandWastesby ICP-MS

Hakanson, L.,Jansson, M., 1983. Principles of Lake Sedimentology, Springer Verlag, Berlin.

Kibaroğlu, A., 2008. Meriç Nehir Havzası Sınıraşan Su Politikaları. 5. Dünya Su Forumu, Türkiye Bölgesel Su Toplantıları: Taşkın Konferansı, 19-20 HAZİRAN 2008, EDİRNE.

Köse, E., Çiçek, A., Uysal, K., Tokatlı, C., Emiroğlu, Ö., Arslan, N., 2015. Heavy Metal Accumulations in Water, Sediment and Some Cyprınıdae Fish Species From Porsuk Stream (Turkey). Water Environment Research, 87 (3): 195-204.

Köse, E., Emiroğlu, Ö., Çiçek, A., Tokatl1, C., Başkurt, S., Aksu, S., 2018. Sediment Quality Assessment in Porsuk Stream Basin (Turkey) From a Multi-Statistical Perspective. Polish Journal of Environmental Studies, 27 (2): 747-752.

Köse, E., Tokatlı, C., Çiçek, A., 2014. Monitoring Stream Water Quality: A Statistical Evaluation. Polish Journal of Environmental Studies, 23 (5): 1637-1647

Li, F.Y., Fan, Z.P., Xiao, P.F., Oh, K., Ma, X.P., Hou, W., 2009. Contamination, Chemical Speciation and Vertical Distribution of Heavy Metals in Soils of an Old and Large İndustrial Zone in Northeast China. Environmental Geology, 54, 1815-1823.

Liu, C. W., Lin, K. H., Kuo, Y. M., 2003. Application of Factor Analysis in the Assessment of Ground Water Quality in a Blackfoot Disease Area in Taiwan. Sci Total Environ, 30: 77-89.

Shrestha, S., Kazama, F., 2007. Assessment of Surface Water Quality Using Multivariate Statistical Techniques: A Case Study of the Fujiriver Basin; Japan. Environmental Modelling \& Software, 22, 464-475.

Shrivastava, P.,Saxena, A., Swarup, A., 2003. Heavy Metal Pollution in a Sewage-Fed Lake of Bhopal, (M. P.) India. Lakes \& Resevoirs: Research and Management, 8:1-4. 
Taş, B., Tepe, Y., Ustaoğlu, F., Alptekin, S., 2019. Benthic Algal Diversity and Water Quality Evaluation by Biological Approach of Turnasuyu Creek, NE Turkey. Desalination and Water Treatment, 155: 402-415.

Tokatl1, C., 2014. Drinking Water Quality of a Rice Land in Turkey by a Statistical and GIS Perspective: İpsala District. Polish Journal of Environmental Studies, 23 (6): 2247-2258.

Tokatl1, C., 2015. Assessment Of The Water Quality in The Meriç River: As an Element of the Ecosystem in the Thrace Region of Turkey. Polish Journal of Environmental Studies. 24 (5): 2205-2211.

Tokatlı, C., 2017. B1o - Ecological and Statıstıcal Risk Assessment of Toxic Metals in Sediments of a Worldwide Important Wetland: Gala Lake National Park (Turkey). Archives of Environmental Protection, 43 (1): 34-47.

Tokatlı, C., 2019a. Water and Sedıment Qualıty Assessment of the Lıfeblood of Thrace Regıon (Turkey): Meriç Rıver Basin. Fresenius Environmental Bulletin, 28 (5): 4131-4140.

Tokatlı, C., 2019b. Sediment Quality of Ergene River Basin: Bio - Ecological Risk Assessment of Toxic Metals. Environmental Monitoring and Assessment, 191 (11): 1-12.

Tokatlı, C., Baştatlı, Y., 2016. Trace and Toxic Element Levels in River Sediments. Polish Journal of Environmental Studies, 25 (4): 17151720 .

Tokatlı, C., Gürbüz, E., 2014. Enez İlçesi ve Yeni Karpuzlu Beldesi Yerel Halkının (Edirne) Gala Gölü Milli Parkı Algılarının Sosyoekonomik ve Ekolojik Açıdan Değerlendirilmesi. International Journal of Social and Economic Sciences, 4 (2): 01-05.

Tokatlı, C., Çiçek, A., Köse, E., 2013. Groundwater Quality Of Türkmen Mountain (Turkey). Polish Journal of Environmental Studies, 22 (4): 1197-1208.

Tokatlı, C., Emiroğlu, Ö., Çiçek, A, Köse, E., Başkurt, S., Aksu, S., Uğurluoğlu, A., Şahin, M., Baştatlı, Y., 2016. Investigation of Toxic Metal Bioaccumulations in Fishes of Meriç River Delta (Edirne). Anadolu Unıversıty Journal of Science and Technology - C Life Sciences and Biotechnology, 5 (1): 1-11.

Tokatlı, C., Köse, E., Çiçek, A., 2014. Assessment of The Effects of Large Borate Deposits on Surface Water Quality by Multi Statistical Approaches: A Case Study of the Seydisuyu Stream (Turkey). Polish Journal of Environmental Studies, 23 (5): 1741 -1751.

Tokatlı, C., Köse, E., Uğurluoğlu, A., Çiçek, A., Emiroğlu, Ö., 2014. Gala Gölü (Edırne) Su Kalitesinin Coğrafi Bilgi Sistemi (CBS) Kullanılarak Değerlendirilmesi. Sigma Journal of Engineering and Natural Sciences, 32: 490-501.

Tokatlı, C., Köse, E., Arslan, N., Çiçek, A., Emiroğlu, Ö., Dayığlu, H., 2016. Ecosystem Quality Assessment of an Aquatic Habitat in a Globally Important Boron Reserve: Emet Stream Basin (Turkey). International Journal of Environment and Pollution, 59 (2/3/4): 116-141.

Ustaoğlu, F., Tepe, Y., Aydin, H., Akbaş, A., 2017. Investigation of Water Quality and Pollution Level of Lower Melet. Alınteri Zirai Bilimler Dergisi, 32 (1): 69-79.

Ustaoğlu, F., Tepe, Y., 2018. Pazarsuyu Deresi (Giresun, Türkiye) Sediment Kalitesinin Çok Değişkenli İstatistik Yöntemlerle Belirlenmesi. Türk Tarım - Gida Bilim ve Teknoloji Dergisi, 6 (3): 304-312.

Ustaoğlu, F., Tepe, Y., 2019. Water Quality and Sediment Contamination Assessment of PazarsuyuStream, Turkey Using Multivariate Statistical Methods and Pollution Indicators. International Soil and Water Conservation, 7: 47-56. 